\title{
С.В. КРАСНИКОВ
}

\section{МОДЕЛИРОВАНИЕ И АНАЛИЗ СОБСТВЕННЫХ КОЛЕБАНИЙ СИСТЕМЫ ТФО С ТУРБИНОЙ 500 МВT}

Проведен анализ собственных колебаний системы турбоагрегат-фундамент-основание с турбиной мощностью 500 МВт в частотном диапазоне приближенном к частоте колебаний электромагнитной природы от генератора. Объектом исследования является система турбоагрегат-фундамент-основание.. Для исследования выбрана система с паровой турбиной, которая содержит несколько типовых корпусов. Для моделирования и проведения численных расчетных исследований использован метод конечных элементов. Построены геометрические и конечно-элементные модели системы турбоагрегат-фундаментоснование с учетом особенностей взаимодействия гибких корпусов турбины с фундаментом. Проведены расчеты собственных колебаний. Получены собственные частоты и формы колебаний. Полученные результаты дают качественную оценку причин повышенной вибрации отдельных элементов рассматриваемой системы.

Ключевые слова: вибрация, паровая турбина, система турбоагрегат-фундамент-основание, метод конечных элементов, собственные частоты и формы колебаний, фундамент.

\section{С.В. КРАСНІКОВ}

\section{МОДЕЛЮВАННЯ ТА АНАЛІЗ ВЛАСНИХ КОЛИВАНЬ СИСТЕМИ ТФО 3 ТУРБІНОЮ 500 МВТ}

Проведено аналіз власних коливань системи турбоагрегат-фундамент-основа. Система включає до себе залізобетонний фундамент, парову турбіну потужністю 500 МВт 3 п’яти корпусів, генератор та чотири конденсатори. Для дослідження обрана система $з$ паровою турбіною, що містить кілька типових корпусів. Актуальність проведеного дослідження зумовлена наявністю у системах турбоагрегат-фундамент-основа з великим часом експлуатації та зі значним відпрацюванням базового ресурсу підвищених рівнів вібрації. 3 іншої сторони актуальність та новизна результатів пов'язана з відсутністю попередніх досліджень 3 наведеного об'єкту та предмету досліджень. Розглядається система з паровою турбіною, що має чотири типових однакових гнучких корпуса та один жорсткий корпус великої ваги. Було розглянуто власні коливання системи турбоагрегатфундамент-основа у частотному діапазоні наближеному до частоти коливань електромагнітної природи від генератора. Об'єктом дослідження є система турбоагрегат-фундамент-основа. Для моделювання та проведення чисельних розрахункових досліджень використаний метод скінчених елементів. Побудовано геометричні та скінчено-елементні моделі системи турбоагрегат-фундамент-основа 3 урахуванням особливостей взаємодії гнучких корпусів турбіни з фундаментом. Моделювання фундаменту виконано за допомогою системи з стрижневих та масових скінчених елементів. Жорсткий корпус парової турбіни та генератор моделювались за допомогою системи масових скінчених елементів. Найбільш гнучкі корпуса парової турбіни моделювались за допомогою системи з оболонкових, стрижневих та масових скінчених елементів. Основа моделювалась за допомогою системи жорсткостей та граничних умов. Конденсатори моделювались за допомогою системи жорсткостей та граничних умов. Особливістю розрахункових моделей є докладне трьохвимірне моделювання гнучких корпусів парової турбіни. Застосована методика моделювання є унікальною та дозволяє проводити докладний аналіз з власних коливань всієї системи Проведено розрахунки власних коливань. Отримано власні частоти й форми коливань. Отримані результати дають якісну оцінку власних коливань окремих елементів розглянутої системи турбоагрегат-фундамент-основа та системи у цілому. Результати розрахунків було використано при дослідженні причин підвищеної вібрації системи турбоагрегат-фундаментоснова та її окремих елементів.

Ключові слова: вібрація, парова турбіна, система турбоагрегат-фундамент-основа, метод скінчених елементів, власні частоти та форми коливань, фундамент.

\section{S.V. KRASNIKOV}

\section{MODELING AND ANALYSIS OF OWN OSCILLATIONS OF THE TFB WITH TURBINE 500 MW}

The analysis of the own oscillations of the turbounit- foundation-base system is carried out. The system includes a reinforced concrete foundation, a $500 \mathrm{MW}$ turbine with five bodies, a generator and four condensers. To study the chosen system with a steam turbine, which contains several typical buildings. The relevance of the study is due to the presence of turbounit-foundation-base systems with a long operating time and a significant development of the base resource of increased levels of vibration. On the other hand, the relevance and novelty of the results is due to the lack of previous research on the given object and subject of research. A system with a steam turbine with four typical identical flexible housings and one rigid body of high weight is considered. The system of turbinebase-base in the frequency range close to the frequency of oscillations of electromagnetic nature from the generator was considered. The object of the study is a turbo-base-base system. The method of finite elements is used for modeling and conducting numerical calculations. The geometric and finite-element models of the turbo unit-foundation-base system are constructed taking into account the features of the interaction of flexible bodies of the turbine with the foundation. The modeling of the foundation is done using a system of core and mass finite element. The rigid body of the steam turbine and the generator were modeled using a system of massive finite elements. The most flexible bodies of the steam turbine were modeled using a shell, core and mass finite element system. The basis was modeled using the system of stiffness and boundary conditions. Capacitors were modeled using a system of stiffness 
and boundary conditions. The peculiarity of the calculation models is the detailed three-dimensional modeling of flexible bodies of the steam turbine. The applied simulation technique is unique and allows us to carry out a detailed analysis of the system's own oscillations. The calculations of proper oscillations have been carried out. Own frequencies and forms of oscillations are obtained. The obtained results give a qualitative estimation of the internal oscillations of separate elements of the considered system of the turboaggregate-foundation-base and the system as a whole. The results of the calculations were used in the study of the causes of increased vibration of the turbo unit-foundation-base system and its individual elements.

Key words: vibration, steam turbine, turbounit-foundation-base system, finite element method, own frequencies and forms of oscillations, foundation.

Введение. Энергетический комплекс развитых стран базируется на использовании атомной и возобновляемой энергетики. Значительная часть атомных электростанций использует в качестве основных элементов энергетических установок системы турбоагрегат-фундамент-основание (ТФО). В качестве турбин для этих систем используются системы мощностью 500 МВт и более. Первоначально энергоблоки атомных электростанций отечественного производства использовали системы ТФО с турбинами мощностью 500 МВт. Отечественные энергоблоки используют турбины, которые были разработаны ПОАТ «Харьковский турбинный завод» имени С.М. Кирова (сейчас АО «Турбоатом») на рубеже 1960-1970 годов коллективами ученых и инженеров г. Харькова под общим управлением генерального конструктора паровых и газовых турбин Юрия Фёдоровича Косяка. Современное развитие паровых турбин этого направления было продолжено коллективами авторов под руководством д.т.н. Бойко А.В., д.т.н. Солодова В.Г., д.т.н. Воробьева Ю.С., д.т.н. Шульженко Н.Г., д.т.н. Жовдака В.А., генерального конструктора АО «Турбоатом» Левченко Е.В., главного конструктора паровых турбин Швецова В.Л. и его заместителей Гришина Н.Н., Кожешкурта И. И.. Значительный вклад внесли несколько поколений рядовых сотрудников с большим стажем, опытом и навыками решения научных и практических задач. Многие из них по разным причинам ушли от задач турбиностроения, но благодаря ветеранам и новому поколению АО «Турбоатом» имеет ресурсы и возможности наращивания производства и проектирования новых турбоагрегатов. В силу негативных процессов в нашем обществе, развитию энергетического комплекса, строительству новых энергоблоков и производству новых турбогенераторов уделяется недостаточно внимания. Это согласуется с общими планами стран, которые относят к развитым. Согласно планам этих стран к 2040 году планируется полное прекращение выработки энергии атома на Украине. Что возможно при полной потери промышленных ресурсов и превращении страны в аграрносырьевой придаток. Это позволит странам с выработанными научными и прочими ресурсами называться развитыми, но не отвечает интересам страны, в которой мы живем. Новые изменения в нашей стране дают надежду на позиционировании ее развития, в частности в области промышленности и энергетики. Это несомненно повысит уровень жизни граждан и приведет к созданию турбин нового поколения и ступенчатой модернизации имеющего парка систем ТФО, в частности с турбинами 500 МВт и выше. При проектировании турбин 500 МВт было решено множество задач, которые обеспечили их длительную эксплуатацию. Однако на данном этапе большая часть турбин мощностью 500 МВт уже выработали свой проектный ресурс. При этом часть турбин имеют повышенную вибрацию, характер которой позволяет сделать выводы о значительном влиянии на их значения вибрации от электромагнитной составляющей генератора. Исследования в этой области на стадии проектирования не выполнялись в достаточном объеме. Однако они представляют значительную актуальность [1-4].

Цель работы. Необходимо провести моделирование и анализ собственных колебаний системы ТФО с турбиной 500 МВт соответствующих частоте вибрации от электромагнитной составляющей генератора. Объектом проведенных исследований является система ТФО с наиболее гибкими элементами турбины 500 МВт. Предметом исследования являются характеристики собственных колебаний системы ТФО с наиболее гибкими элементами турбины.

Математическая модель. Для моделирования и получения характеристик собственных колебаний используется метод конечных элементов. Основной функционал в общем виде:

$$
L(t, O, q)=R(t)
$$

где $O$ - различные состояния связи корпуса турбины с фундаментом,

$L$ - уравнение Лагранжа 2-го рода,

$q$ - обобщенные перемещения,

$R$ - внешние силы.

В методе конечных элементов [5-7] выражение (1) обычно записывается в следующем матричном виде:

$$
[M]\{\ddot{q}(t)\}+[C]\{\dot{q}(t)\}+[K]\{q(t)\}=0,
$$

где $M$-матрица масс,

$C$ - матрица демпфирования,

$K$ - матрица жесткости.

Собственная частота системы $p_{j}$ определяется из формулы (3):

$$
\operatorname{det}\left[K-p_{j}^{2} M\right]=0 \text {. }
$$

Описание расчетной модели. На основе ранее разработанных геометрических моделей фундамента и корпуса цилиндра низкого давления был построен ряд конечно-элементных моделей [8 - 13]. Для проведения расчетов выбрана модель из 27040 узлов и 23165 конечных элементов. Внешний вид моделей показан на рис. 1. Фундамент моделировался системой стержневых элементов. Наиболее гибкие части турбины моделировались системой пластин, стержней и масс. Жесткие части турбины и генератор моделировались системой масс. 


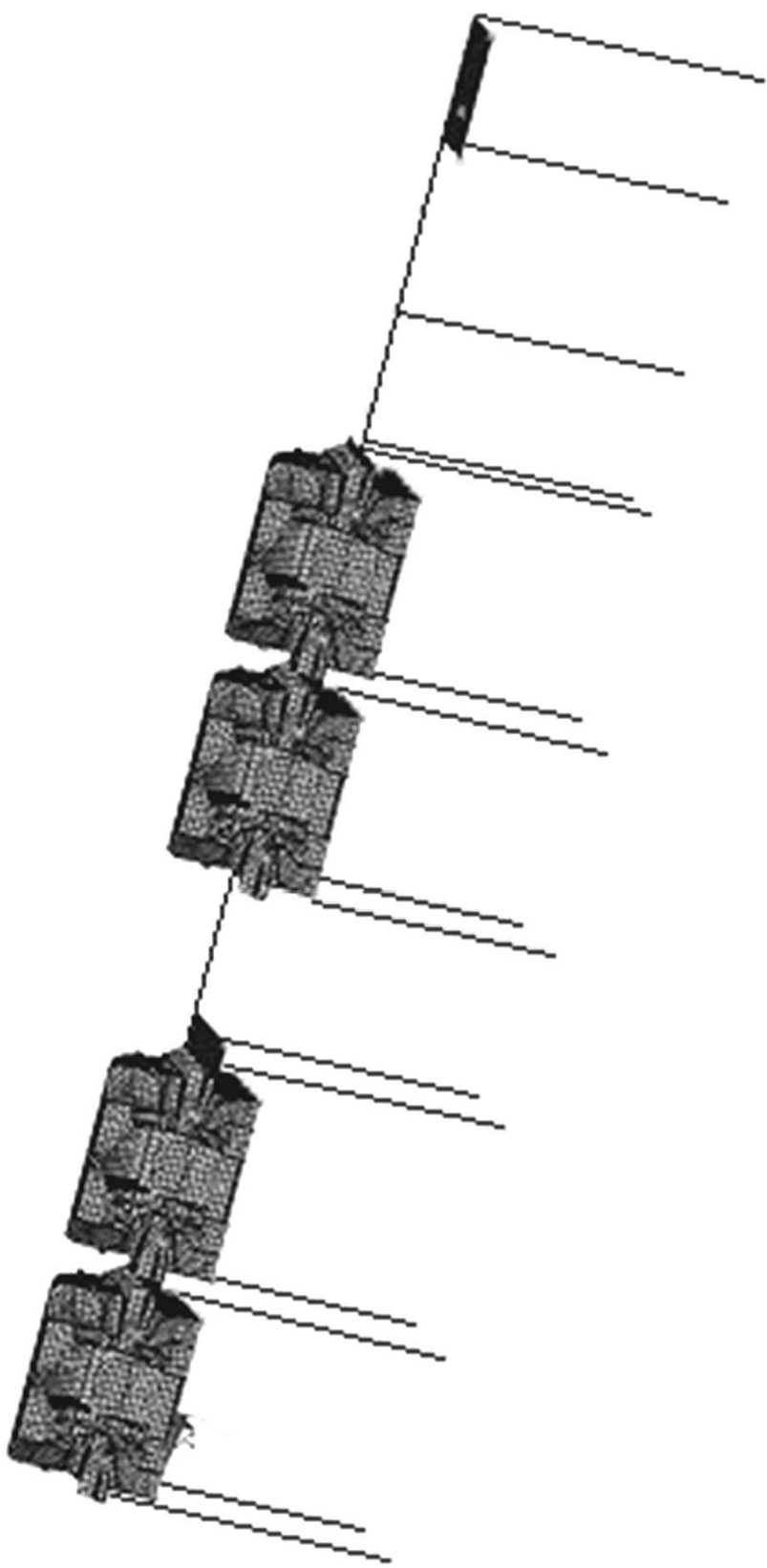

Рисунок 1 - Расчетная модель системы ТФО с турбиной $500 \mathrm{MBT}$
Связь гибких частей турбины с фундаментом моделировалось системой жесткостей, которая учитывает особенности взаимодействия турбины с фундаментом [14 - 21].

Результаты численных исследований. Были проведены расчеты собственных колебаний системы ТФО вблизи частоты соответствующей частоте вибрации от электромагнитной составляющей генератора. Результаты расчетов представлены в табл. 1 и на рис. $2-6$.

Таблица 1 - Собственные частоты для системы турбоагрегат фундамент-основание в диапазоне 98 - 102 Гц, Гц

\begin{tabular}{|c|c||c|c||c|c|}
\hline № & Частота & № & Частота & № & Частота \\
\hline 1 & 98,000 & 11 & 99,483 & 21 & 101,01 \\
\hline 2 & 98,317 & 12 & 99,697 & 22 & 101,01 \\
\hline 3 & 98,598 & 13 & 100,16 & 23 & 101,01 \\
\hline 4 & 98,731 & 14 & 100,17 & 24 & 101,05 \\
\hline 5 & 99,048 & 15 & 100,25 & 25 & 101,31 \\
\hline 6 & 99,303 & 16 & 100,29 & 26 & 101,51 \\
\hline 7 & 99,374 & 17 & 100,58 & 27 & 101,61 \\
\hline 8 & 99,383 & 18 & 100,67 & 28 & 101,73 \\
\hline 9 & 99,421 & 19 & 100,91 & 29 & 101,82 \\
\hline 10 & 99,451 & 20 & 100,94 & 30 & 101,93 \\
\hline
\end{tabular}

Из табл. 1 видно, что в районе 100 Гц имеется достаточно много собственных частот. Из рис. 2-6 видно, что большая часть собственных форм характеризуется локальными колебаниями пластин верхней части наиболее гибких корпусов турбины. При этом большое количество собственных форм соответствуют кратным собственным частотам. В связи с тем, что гибкие корпуса турбины абсолютно идентичны, то наличие кратных частот связано с различной жесткостью фундамента в местах опирания на него корпусов турбины. Фактически имеет место «расстройка колебаний». Касательно наиболее близких к частоте 100 Гц собственных колебаний можно отметить следующее.На рис. 2 показана собственная форма на частоте 100,16 Гц, которая определяется интенсивными колебаниями торцовой стенки и стенки над опорой подшипника крышек корпусов турбины наиболее удаленных от генератора. Аналогичные формы колебаний для корпусов наиболее близких к генератору имеют собственные формы колебаний для частоты 100,17 Гц (рис. 3).

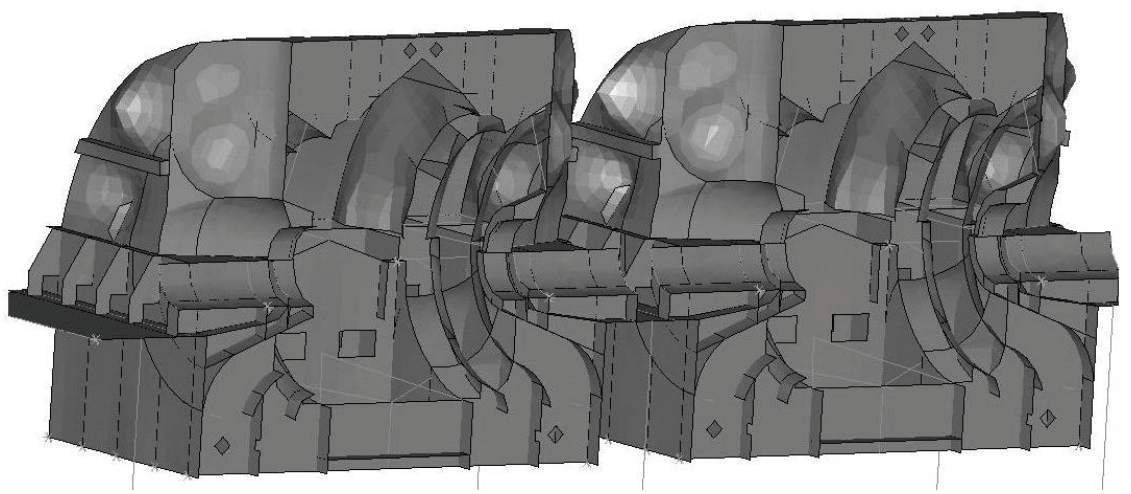

Рисунок 2 - Собственная форма колебаний на частоте 100,16 Гц 


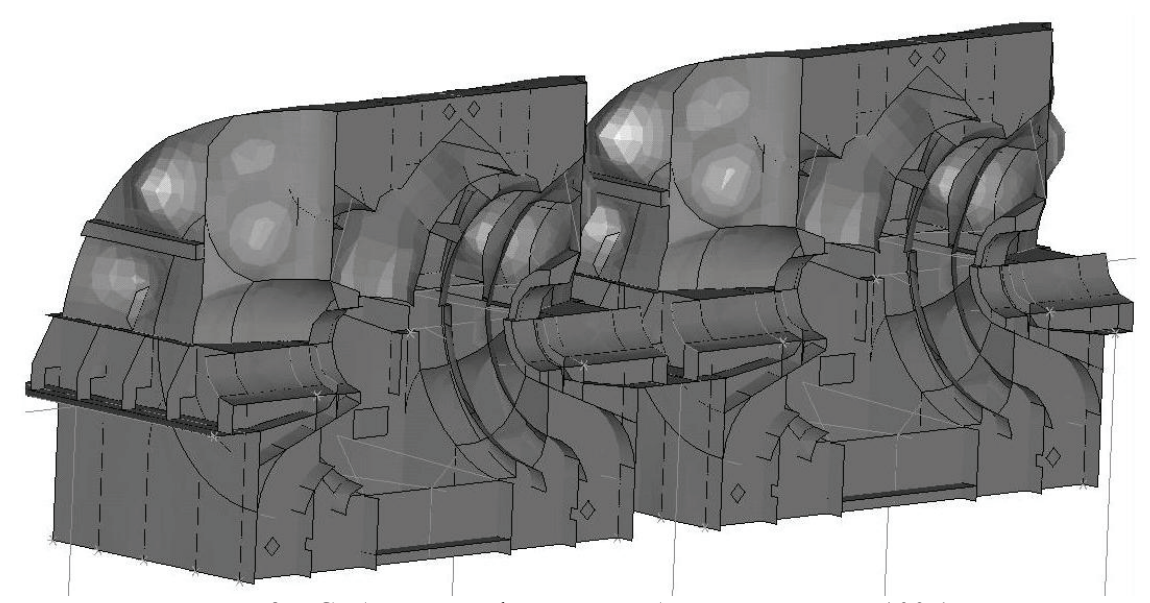

Рисунок 3 - Собственная форма колебаний на частоте 100,17 Гц

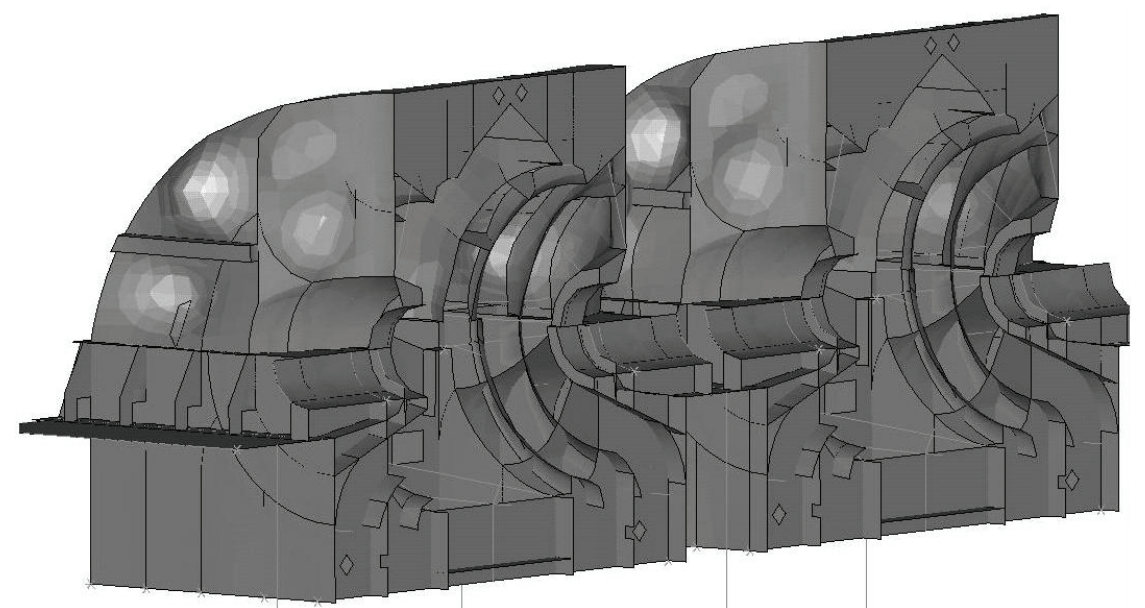

Рисунок 4 - Собственная форма колебаний на частоте 100,25 Гц

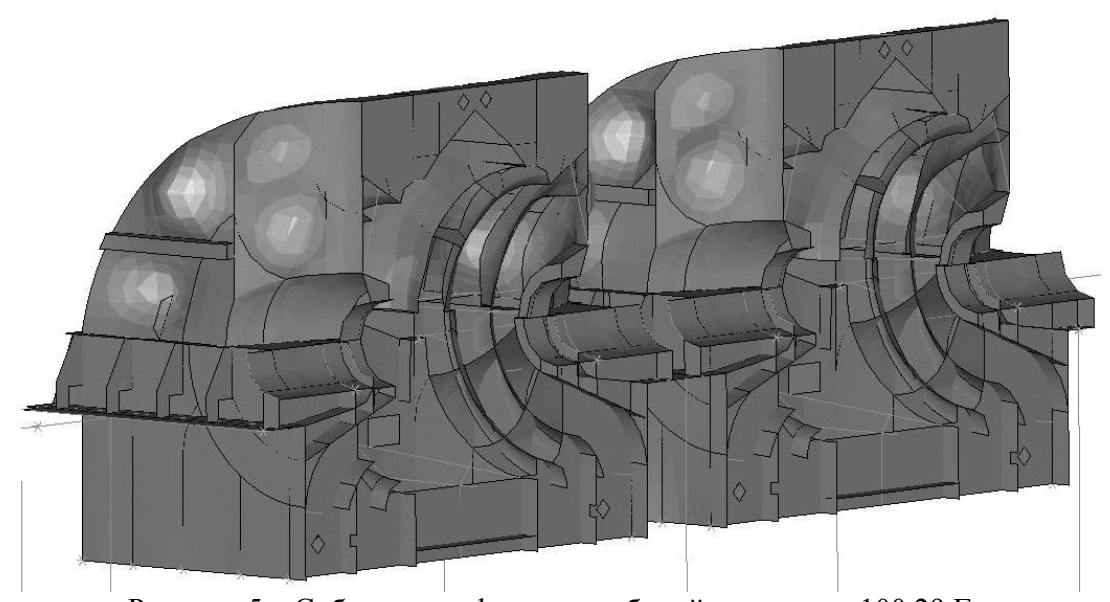

Рисунок 5 - Собственная форма колебаний на частоте 100,29 Гц

Собственные формы на частотах 100,25 Гц и 100,29 Гц (рисунки 4 и 5, соответственно) практически совпадают с приведенными на рисунках 2 и 3. Отличие наблюдается в перераспределении максимумов амплитуд между стенками верхних частей корпусов турбины. Приведенная на рис. 6 собственная форма на частоте 100,68 Гц также характеризуется колебаниями стенок корпусов соответствующим опорам валопровода $1,2,7,8$. Остальные собственные формы колебаний в указанном диапазоне частот имеют по- добный характер показанным на рис. 2 - 6 формам собственных колебаний.

Выводы. В результате моделирования и анализа собственных колебаний системы ТФО определены места повышенной вибрации на частотах близких к частоте возмущения колебаний электромагнитной природы от генератора. Полученные результаты позволяют оценить причины и места повышенной вибрации наиболее гибких корпусов турбины. 


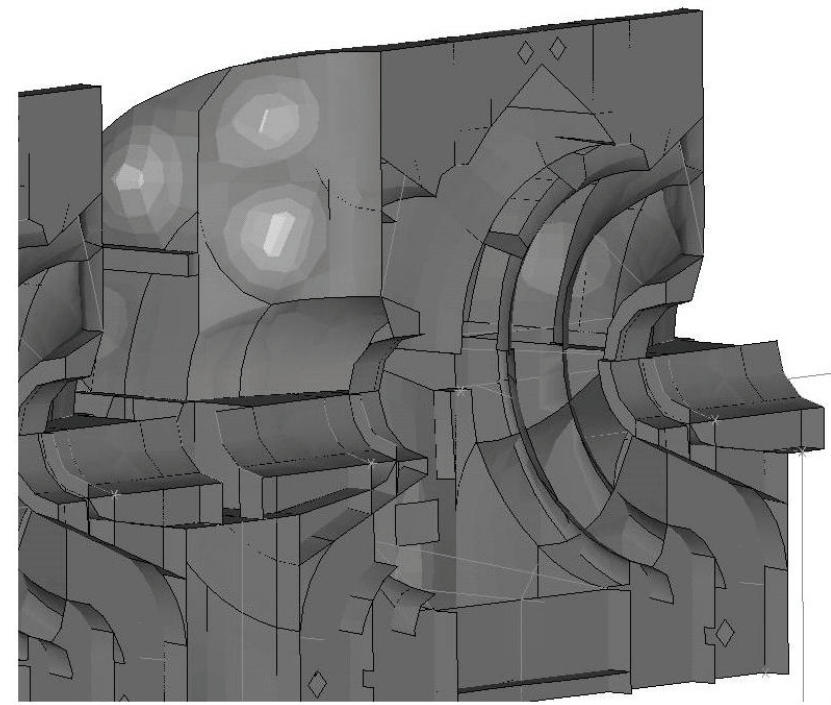

Рисунок 6 - Собственная форма колебаний на частоте 100,68 Гц

\section{Список литературы}

1. Косяк Ю.Ф. и др. Паротурбинные установки атомных электростанций / ред. Косяк Ю.Ф. Москва: Энергия, 1978. $312 \mathrm{c}$.

2. Трояновский Б.М. Турбины для атомных электростанций. Москва: Энергия, 1978. 182 с.

3. Левченко Е.В., Швецчов В.Л., Кожешкурт И.И., Лобко А.Н. Опыт ОАО « ТурбоАтом» в разработке и модернизации турбин для АЭС. СПб: Энергетические и теплотехнические процессы и оборудование. 2010. № 3. С. 5-11.

4. Субботин В.Г., Левченко Е.В., Швецов В.Л. Паровые турбины ОАО «Турбоатом» для тепловых электростанций. Харьков: Вестник НТУ «ХПИ». 2009. № 3. С. 6-17.

5. Еременко С.Ю. Методы конечных элементов в механике деформируемых тел. Харьков: Основа, 1991. $271 \mathrm{c}$.

6. Галлагер Р. Метод конечных элементов. Основы. Москва: Мир, 1984. 428 с.

7. HITACHI. Turbine and Generator Foundation Design and construction \& recommendation. Tokyo: Japan. 2009. 104 p.

8. Назаренко С.А., Ткачук Н.А. Обзор некоторых ключевых направлений исследований ученых НТУ «ХПИ» в области динамики конструкций. Харьков: Вестник НТУ «ХПИ». 2017. № 39. С.49-56.

9. Ларін А., Чумаченко О. Співпраця запорізьких авіадвигунобудівних підприємств 3 провідними вченими України в галузі динамічної міцності в 1950-1970-х рр. Харків: Дослідження з історії техніки. 2016. № 23. С.72-78.

10. Жовдак В.А., Красников С.В., Степченко А.С. Решение задачи статистической динамики машиностроительных конструкций с учетом случайного изменения параметров. Харьков: Проблемы машиностроения. 2004. Т.7, № 3. С. $39-47$.

11. Zhiqiang $H u$, Wei Wang, Puning Jiang, Qinghua Huang, Jianhua Wang, Sihua Xu, Jin He and Lei Xiao A Seismic Analysis on Steam Turbine Considering Turbine and Foundation Interaction. Düsseldorf: ASME Turbo Expo 2014: Turbine Technical Conference and Exposition. 2014. no. V01BT27A041. P. 1-8.

12. Alan Turnbull Corrosion pitting and environmentally assisted small crack growth. Proceedings. Mathematical, Physical, and Engineering Sciences. London:The Royal Society. 2014. no. 20140254. P. 1-19.

13. Chowdhury Indrajit, Dasguptu P. Shambhu Dynamics of Structure and foundation a unified approach. Leiden: CRC Press. 2009. 616 p.

14. Рунов Б.Т. Исследование и устранение вибрации паровых турбоагрегатов. Москва: Энергоиздат, 1982. 352 с.

15. Yu M., Feng N., Hahn E. J. An equation decoupling approach to identify the equivalent foundation in rotating machinery using modal parameters. Journal of Sound and Vibration. 2016. Vol. 365. P. 182-198.

16. Xu X.P., Han Q.K., Chu F.L. Nonlinear vibration of a generator rotor with unbalanced magnetic pull considering both dynamic and static eccentricities. Archive of Applied Mechanics. 2016. Vol. 86. P. 1521-1536.

17. Jalali M.H., Ghayour M., Ziaei Rad S., Shahriari B. Dynamic analysis of a high speed rotor-bearing system. Measurement: Journal of the International Measurement Confederation. 2014. Vol. 53. P. 1-9.

18. Zhang Yang, Yanlong Jiang, Guoyuan Zhang Bending fault evaluation for the HP-IP rotor system of the nuclear steam turbine based on the dynamic model. Journal of Vibroengineering. 2017. Vol. 19. P. 3364-3379.

19. Minli Yu, Ningsheng Feng, Eric J. Hahn Corrigendum to "An equation decoupling approach to identify the equivalent foundation in rotatin $\mathrm{g}$ machi nery using modal parameters". J. Sound Vib. 2016. Vol. 365. P. 182-198.

20. Minli Yu, Jike Liu, Ningsheng Feng, Eric J. Hahn Experimental evaluation of a quasi-modal parameter based rotor foundation identification technique. J. Sound Vib. 2017. Vol. 411. P. 165-192.

21. Красников С.В. Моделирование и анализ вибрационных характеристик корпуса паровой турбины большой мощности. Харьков: Вестник НТУ «ХПИ». 2017. № 39. C.23-26.

\section{Bibliography (transliterated)}

1. Kosyak Yu.F. and other Paroturbinnye ustanovki atomnykh elektrostantsii / red. Kosyak Yu.F. [Steam turbine installations of atomic power plants]. Moscow: Energiya. 1978. 312 p. [in Russian].

2. Troyanovskii B.M. Turbiny dlya atomnykh elektrostantsii [Turbines for nuclear power plants]. Moscow: Energiya, 1978. 182 p. [in Russian].

3. Levchenko E.V., Shvetsov V.L., Kozheshkurt I.I., Lobko A.N. Opyt OAO «TurboAtom» v raz-rabotke i modernizatsii turbin dlya AES [Experience of OJSC "TurboAtom" in the development and modernization of turbines for nuclear power plants.], Energeticheskie i teplotekhnicheskie protsessy i oborudovanie. SantPeterburg. 2010. № 3. P. 5-11 [in Russian].

4. Subbotin V.G., Levchenko E.V., Shvetsov V.L. Parovye turbiny OAO "Turboatom" dlya teplovykh elektrostantsii [Tur- 
boatom steam turbines for thermal power plants]. Vestnik Nats. tekhn. un-ta "KhPI". Kharkiv: 2009. № 3. P. 6-17 [in Russian].

5. Eremenko S.Yu. Metody konechnykh elementov v mekhanike deformiruemykh tel [Finite-element methods in mechanics of deformable bodies.]. Kharkiv: Osnova, 1991. 271 p. [in Russian].

6. Gallager $R$. Metod konechnykh elementov. Osnovy [The finite element method. Basedata]. Moscow: Mir, 1984. 428 p. [in Russian].

7. HITACHI. Turbine and Generator Foundation Design and construction \& recommendation. Tokyo: Japan, 1984. 104 p.

8. Nazarenko S.A., Tkachuk N.A. Obzor nekotorykh klyuchevykh napravlenii issledovanii uchenykh NTU «KhPI» v oblasti dinamiki konstruktsii. [Review of the main directions of research of scientists of NTU "KhPI" in the field of dynamics of constructions]. Visnik NTU «KhPI». Kharkiv: 2017. № 39. P. 49-56 [in Russian].

9. Larin A., Chumachenko O. Spivpratsya zaporiz'kikh aviadvigunobudivnikh pidpriemstv $\mathrm{z}$ providnimi vchenimi Ukraïni v galuzi dinamich-noï mitsnosti v 1950-1970-kh rr. [Cooperation Zaporizhzhya aviation engine-building companies with the leading scientists of Ukraine in the field of dynamic strength in the 1950-1970.] Doslidzhennya $\mathrm{z}$ istorii tekhniki. Kharkiv: 2016. № 23. P. $72-78$ [in Ukrainian].

10. Zhovdak V.O., Krasnikov S.V., Stepchenko O.S. Reshenie zadachi statisticheskoi dinamiki ma-shinostroitel'nykh konstruktsii s uchetom slu-chainogo izmeneniya parametrov [The solution of the problem of the statistical dynamics of the machine-building constructions taking into account a random change in parameters. Kharkiv: Engineering problems]. Problemy mashinostroeniya. Kharkiv: 2004. № 3. P. 39-47 [in Russian].

11. Zhiqiang Hu, Wei Wang, Puning Jiang, Qinghua Huang, Jianhua Wang, Sihua Xu, Jin He and Lei Xiao A Seismic Analysis on Steam Turbine Con-sidering Turbine and Foundation Interaction. ASME Turbo Expo 2014: Turbine Technical Conference and Exposition, Düsseldorf: 2004. V01BT27A041. P. $1-8$.

12. Alan Turnbull Corrosion pitting and environmen-tally assisted small crack growth. Proceedings. Mathematical, Physical, and Engineering Sciences, London: The Royal Society. 2014. № 20140254. P. 1-19.

13. Chowdhury Indrajit, Dasguptu P. Shambhu Dynamics of Structure and foundation a unified approach. Leiden: CRC Press, 2009. $616 \mathrm{p}$.

14. Runov B.T. Issledovanie i ustranenie vib-ratsii parovykh turboagregatov [Research and elimination of the vibration of the steam turbine units]. Moscow: Energoizdat, 1982. 352 p. [in Russian].

15. Gallager $R$. Metod konechnykh elementov. Osnovy [The finite element method. Basedata]. Moscow: Mir, 1984. 428 p. [in Russian].

16. Xu X.P., Han Q.K., Chu F.L. Nonlinear vibration of a generator rotor with unbalanced magnetic pull considering both dynamic and static eccentricities. Archive of Applied Mechanics. 2016. № 86. P. 1521-1536.

17. Jalali M.H., Ghayour M., Ziaei Rad S., Shahriari B. Dynamic analysis of a high speed rotor-bearing system. Measurement: Journal of the International Measurement Confederation. 2014. № 53. P. 1-9.

18. Zhang Yang, Yanlong Jiang, Guoyuan Zhang Bending fault evaluation for the HP-IP rotor system of the nuclear steam turbine based on the dynamic model. Journal of Vibroengineering. 2017. № 19. P. 3364-3379.

19. Minli Yu, Ningsheng Feng, Eric J. Hahn Corrigendum to" An equation decoupling approach to identify the equivalent foundation in rotatin $\mathrm{g}$ machi nery using modal parameters" $\mathrm{J}$. Sound Vib. 2016. № 365. P. 182-198.

20. Minli Yu, Jike Liu, Ningsheng Feng, Eric J. Hahn Experimental evaluation of a quasi-modal parameter based rotor foundation identification technique . J. Sound Vib. 2017. № 411. P. 165-192.

21. Krasnikov S.V. Modelirovanie i analiz vib-ratsionnykh kharakteristik korpusa parovoi tur-biny bol'shoi moshchnosti [Modeling and analysis of the vibration characteristics of a highpower steam turbine hull]. Visnik NTU «KhPI». Kharkiv: 2017. № 39. P. 23-26 [in Russian].

Надійшла (received) 04.06.2019

Відомості про авторів / Сведения об авторах / About the Authors

Красников Сергей Васильевич (Красніков Серzій Васильович, Krasnikov Sergij Vasyl'ovych) кандидат технических наук, доцент, Харьковский национальный автомобильно-дорожный университет: тел. (+038057) 70737-30; e-mail: vsevakr@yandex.ru 